\title{
Forensic importance of maxillary sinus in gender determination: A morphometric analysis from Western Uttar Pradesh, India
}

\author{
Ruhi Sidhu, Sunira Chandra ${ }^{1}$, Parvathi Devi, Neeraj Taneja ${ }^{2}$, Kunal Sah ${ }^{3}$, Navdeep Kaur \\ Department of Oral Medicine and Radiology, Teerthanker Mahaveer Dental College and Research \\ Centre, Moradabad, ${ }^{1}$ Departments of Oral Medicine and Radiology, ${ }^{3}$ Oral Pathology and \\ Microbiology, Saraswati Dental College and Hospital, Lucknow, Uttar Pradesh, ${ }^{2}$ Department of Oral \\ Medicine and Radiology, Rayat and Bahra Dental College, Gharaun, Mohali, Punjab, India
}

\author{
Address for correspondence: \\ Dr. Sunira Chandra, \\ Department of Oral Medicine and \\ Radiology, Saraswati Dental College \\ and Hospital, Faizabad Road, \\ Tiwari Ganj, Lucknow - 227 105, \\ Uttar Pradesh, India \\ E-mail: sunira_chandra1@yahoo.co.in
}

\begin{abstract}
Background: The study of anthropometric characteristics is of fundamental importance to solve problems related to identification. Craniometrical features are included among these characteristics, which are closely connected to forensic dentistry. Radiography is used in forensic for the identification of humans especially in cases where the body is decomposed, fragmented, or burned. Radiology can assist in giving accurate dimensions for which certain formulae can be applied to determine the gender. It has been reported that maxillary sinuses remain intact, although the skull and other bones may be badly disfigured in victims who are incinerated and therefore, that maxillary sinuses can be used for identification. Aim: This study has been carried out to check the accuracy and reliability of maxillary sinus in gender determination using morphometric parameters. Materials and Methods: Lateral cephalogram of 50 subjects ( 25 males and 25 females) were taken and morphometric parameters of maxillary sinus were analyzed using AutoCAD 2010 software (Autodesk, Inc.). Results: The mean area and perimeter of maxillary sinus in males was $1.7261 \mathrm{~cm}^{2}$ and $5.2885 \mathrm{~cm}$ whereas, the mean area and perimeter in females was $1.3424 \mathrm{~cm}^{2}$ and $4.3901 \mathrm{~cm}$. In-group centroids if someone's discriminant function (DF) score is close to 0.838 then the subject are supposed to be male. Whereas, those having DF score closer to -0.838 are supposed to be females. DF analysis showed that, $76 \%$ of the original grouped cases were correctly classified. Hence, the overall sensitivity and specificity was found to be $80 \%$ and $72 \%$. Conclusion: It can be concluded that morphometric analysis (area and perimeter) of maxillary sinus using AutoCAD 2010 software can assist in gender determination.
\end{abstract}

Key words

Forensic odontology, maxillary sinus, morphometric analysis, sex determination

\section{INTRODUCTION}

Identification of corpses is a difficult forensic procedure and it is mandated by laws and social rules..$^{[1]}$ The study of anthropometric characteristics is of fundamental importance to solve problems related to identification. Skeletal remains have been used for sexing the individual as bones of the body are last to perish after death, next to enamel of teeth. ${ }^{[2]}$ Traditionally, radiology has been limited in its applications to forensic medicine in the field of identification. Visual inspection, anatomic measurement

\begin{tabular}{|l|l|}
\hline \multicolumn{2}{|c|}{ Access this article online } \\
\hline Quick Response Code: & Website: \\
\hline ⿴囗十 & www.ejgd.org \\
\cline { 2 - 2 } & \\
\hline & DOI: \\
\hline 口. & $10.4103 / 2278-9626.126213$ \\
\hline
\end{tabular}

and precise measurement of bone dimensions often exceed radiologic contribution, particularly where identification of skeletal remains is required. The most helpful area of the body for comparison radiography is the cranium. ${ }^{[3]}$ Radiography is used in forensic pathology for the identification of humans especially in cases where the body is decomposed, fragmented or burned. The skull, pelvis and femora are the most useful for the radiological determination of gender. ${ }^{[2]}$

It has been reported that the maxillary sinuses remain intact although the skull and other bones may be badly disfigured in victims who are incinerated and therefore, that maxillary sinuses can be used for identification..$^{[1]}$ During fetal development, the paranasal sinuses originate as invagination of the nasal mucosa into the lateral nasal wall, frontal, ethmoid, maxilla and the sphenoid bones. This unique development explains the enormous amount of anatomical variation..$^{[4]}$ Maxillary sinuses are two spaces, which are filled with air, located in the maxillary bone and can be in various sizes and shapes. 
Their walls are thin. The apex of the sinuses can extend into the zygomatic process and can occupy the zygomatic bone. The floor formed by the alveolar process, the first, the second and the third molars and the roots of the canines may elevate the sinuses or may perforate their floor. ${ }^{[1]}$ The maxillary sinus is the largest of the paranasal sinuses and at 10 weeks in utero, is the first to develop. After birth, the sinus continues to pneumatize into the developing alveolar ridge as the permanent teeth erupt. At 12-13 years, the sinus floor is level with the nasal floor and at the age 20 , with the completion of the eruption of the third molars, the pneumatization of the sinus ends and the sinus reaches $5 \mathrm{~mm}$ inferior to the nasal floor. ${ }^{[5]}$ It has been reported that genetic diseases, post infections and environmental factors can affect the sizes of maxillary sinuses. Szilvassy divided the maxillary sinuses into four bases according to their shapes: i.e., triangular, leaf, scapular and renal shaped. It has been reported that triangular sinuses were the most common in both females and males. Maxillary sinuses have also been classified into triangular, oval, curved, rectangular and square shapes..$^{[1]}$ The present study was designed to determine the reliability and accuracy of maxillary sinus (area and perimeter measurement) as a technique for gender identification using morphometric analysis.

\section{MATERIALS AND METHODS}

The present study was carried out in the Department of Oral Medicine and Radiology after required approval from the institutional ethical committee. The study group comprises of 50 subjects (25 males and 25 females) above the age group of 18 years. Healthy subjects were enrolled randomly attending out-patient department and informed consent was obtained. A patient-specific data was recorded in a questionnaire for social history, general history; dental history and oral hygiene. Subjects with the history of facial trauma, fracture of maxillary sinus, congenital developmental abnormalities, sinusitis and cleft palate were excluded from the study.

Lateral cephalogram radiographs were obtained using standard techniques with Villa systemi medicali cephalometric device for rotograph plus (Italy) for extra-oral radiography set at $85 \mathrm{kvp}$ and $10 \mathrm{~mA}$. Kodak intensifying screen was used as image receptor and the X-ray film was developed with Fuji computed radiography capsula automatic processing unit. Area and perimeter of maxillary sinus was measured by marking the outer borders of maxillary sinus with AutoCAD 2010 software (Autodesk, Inc.) on the lateral cephalogram [Figure 1].

Data collected was entered in excel sheet using Windows 7 version and was compiled and prepared to be compatible for the statistical SPSS software. Data analysis was explained under descriptive statistics and inferential statistics. For descriptive statistics frequencies were obtained for all the categorical variables. Although mean, standard deviation, variance and standard error values were calculated for all the numerical variables wherever needed.

\section{RESULTS}

The area and the perimeter were calculated from the software AutoCAD 2010. The mean area in males was $1.7261 \mathrm{~cm}^{2}$ with a standard deviation of 0.2364 and in females was $1.3424 \mathrm{~cm}^{2}$ with a standard deviation of 0.2369 . The mean perimeter in males was $5.2885 \mathrm{~cm}$, whereas the mean perimeter in females was $4.3901 \mathrm{~cm}$ [Table 1]. Hence, showing males have a larger area and perimeter when compared with females. In-group centroids if someone's discriminant function (DF) score is close to 0.838 then the subject are classified as male. Therefore, those having DF score closer to -0.838 then the subject is classified as females [Table 2]. The final result of the DF analysis showed that, $76 \%$ of the original grouped cases were correctly classified. Hence, sensitivity of $20 / 25=80 \%$ and specificity: Of $18 / 25=72 \%$ is obtained [Table 3] Prior probabilities for groups (Male $\&$ Females) is described in Table 4.

\section{DISCUSSION}

Identification on skeletal and decomposing human remains is one of the most difficult skills in forensic medicine. Sex determination is also an important problem in the identification. When the skeleton exists completely, sex can be determined with $100 \%$ accuracy. This estimation rate is $98 \%$ in existence of pelvis and cranium, 95\% with only pelvis and long bones and $80-90 \%$ with only long bones. Next to the pelvis, the skull is the most easily sexed portion of the skeleton, but the determination of sex from the skull is not reliable well until after puberty. Sex estimation can be accomplished using either morphological or metric methodologies. ${ }^{[1]}$

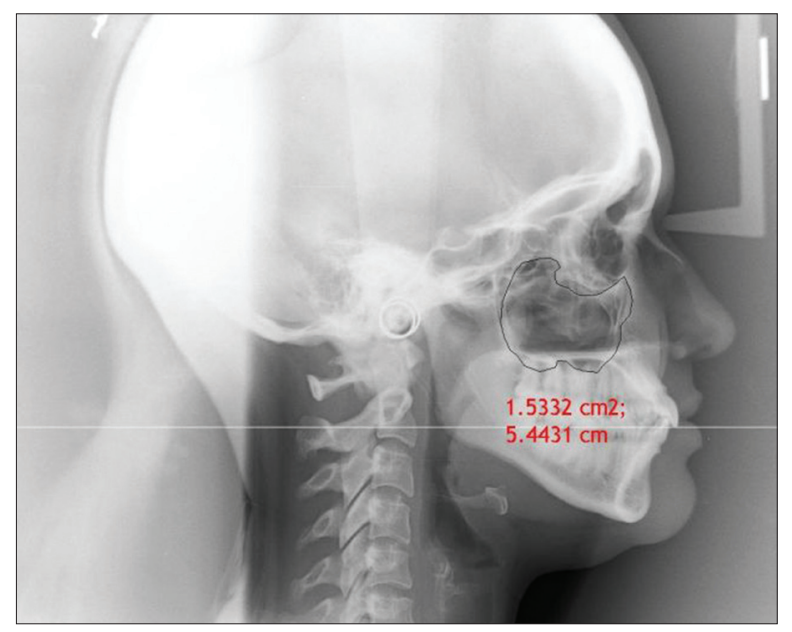

Figure 1: Measuring area and perimeter of maxillary sinus by AutoCAD 2010 software on the lateral cephalogram 


\begin{tabular}{|c|c|c|c|c|c|}
\hline Sex & Mean & Range & Standard deviation & Standard error of mean & Variance \\
\hline \multicolumn{6}{|l|}{ Male } \\
\hline Area $\left(\mathrm{cm}^{2}\right)$ & 1.7261 & 0.9760 & 0.2364 & 0.0473 & 0.0559 \\
\hline Perimeter $(\mathrm{cm})$ & 5.2885 & 2.7518 & 0.5702 & 0.1140 & 0.3251 \\
\hline \multicolumn{6}{|l|}{ Female } \\
\hline Area $\left(\mathrm{cm}^{2}\right)$ & 1.3424 & 1.1674 & 0.2369 & 0.0474 & 0.0561 \\
\hline Perimeter $(\mathrm{cm})$ & 4.3901 & 2.5921 & 0.7521 & 0.1504 & 0.5656 \\
\hline
\end{tabular}

\begin{tabular}{lc}
\hline Table 2: Functions at group centroids & \\
Sex & Function \\
\hline Male & 0.838 \\
Female & -0.838 \\
\hline
\end{tabular}

\begin{tabular}{|c|c|c|c|}
\hline \multicolumn{4}{|c|}{ Table 3: Discriminant function analysis } \\
\hline \multicolumn{4}{|c|}{ Classification results } \\
\hline \multirow[t]{2}{*}{ Sex } & \multicolumn{2}{|c|}{$\begin{array}{l}\text { Predicted group } \\
\text { membership }\end{array}$} & \multirow[t]{2}{*}{ Total } \\
\hline & Male & Female & \\
\hline \multicolumn{4}{|l|}{ Original } \\
\hline \multicolumn{4}{|l|}{ Count } \\
\hline Male & 20 & 5 & 25 \\
\hline Female & 7 & 18 & 25 \\
\hline \multicolumn{4}{|l|}{$\%$} \\
\hline Male & 80.0 & 20.0 & 100.0 \\
\hline Female & 28.0 & 72.0 & 100.0 \\
\hline
\end{tabular}

\begin{tabular}{lccc}
\multicolumn{3}{l}{ Table 4: } & Prior probabilities for \\
& \multicolumn{2}{c}{ Proups (Male \& $\&$ Female) } \\
Sex & Prior & Cases used in analysis \\
\cline { 2 - 4 } & & Un-weighted & Weighted \\
\hline Male & 0.500 & 25 & 25.000 \\
Female & 0.500 & 25 & 25.000 \\
Total & 1.000 & 50 & 50.000 \\
\hline
\end{tabular}

The result of the present study showed that the maxillary sinus exhibits anatomic variability between genders. A significant sex difference was found in relation to maxillary sinus area and perimeter with the mean area in males as $1.7261 \mathrm{~cm}^{2}$ and mean perimeter as $5.2885 \mathrm{~cm}$ whereas, the mean area in females as $1.3424 \mathrm{~cm}^{2}$ and mean perimeter as $4.3901 \mathrm{~cm}$. Hence, showing males have a larger area and perimeter as compared to females [Figure 2]. In group of centroids if someone's DF score is close to 0.838 then the subject is a male. Whereas, those having DF score closer to -0.838 are females. The sensitivity of the discriminant functional analysis was $80 \%(20 / 25)$ and specificity was $72 \%(18 / 25)$.

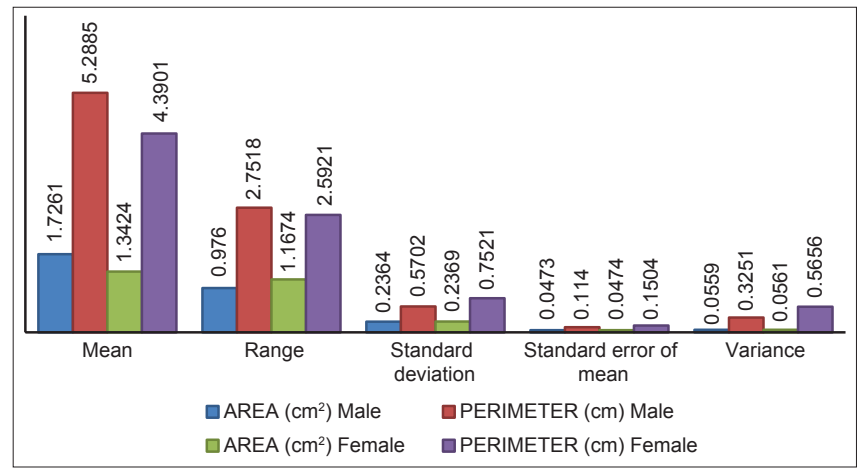

Figure 2: Descriptive statistics of maxillary sinus in males and females

Kim, conducted a study on 561 subjects (363 males and 198 females) using PA view and lateral cephalogram. Manual linear measurements were done using a mathematical formula and the area was calculated. Their results showed right and left sinus size was almost equal with males having larger size when compared to females. ${ }^{[6]}$ Fernandes et al. conducted a study on dried skulls on 53 subjects (13 males; 13 females, European); (13 males; 14 females, Zulu) using neural network and linear measurements and estimated volume. Ethnic and gender variations were found in the different groups and the predictive role of the maxillary sinus in ethnic classification was established. They found that European crania had significantly larger antral volumes than Zulu crania and males had larger volumes than females. Dimensions of European sinuses were larger than those of Zulu sinuses. The medial antral wall of the sinus allowed for ethnic classification. The discriminant analysis allowed for a very successful $90 \%$ ethnic prediction, while gender prediction was ultimately $79 \% .{ }^{[3]}$ Uthman et al. also conducted a study to check the accuracy and reliability of maxillary sinus dimensions measurement in gender classification through the use of reconstructed helical computed tomography (CT) images. A total of 88 patients, of these 43 were men and 45 were women with age range from 20 to 49 years were selected in this study. The width, length and height of the maxillary sinuses in addition to the total distance across both sinuses were measured and found that maxillary sinus height was the best discriminant parameter that could be used to study sexual dimorphism with an overall accuracy of $71.6 \%, 74.4 \%$ of male sinuses and $73.3 \%$ of female sinuses were sexed correctly. The overall percentage for sexing maxillary sinuses correctly was 
73.9\%. It was concluded that reconstructed CT image could provide valuable measurements for maxillary sinuses and could be used for sexing when other methods of sexing are not conclusive. ${ }^{[2]}$ Amusa et al. conducted a study on 24 dried skulls of Nigerians from which the temporal bones had earlier been dissected were studied. A $0^{\circ}$ sinus endoscopy (Telescope) was utilized to visualize the paranasal sinuses and their degree of pneumatization was noted. Vernier caliper was employed to measure the distance between the anterior and posterior nasal spine. The height, width, depth and volume of each of the sinuses were determined. The anatomical variants were noted. In all the paranasal sinuses, the right side was found to be larger than the left except for the maxillary sinus where the left side was found to be larger. ${ }^{[4]}$ Amin and Hassan conducted a study using multi-detector CT (MDCT) scan, eight maxillary sinus measurements were assessed in 96 living non-pathologic Egyptians comprising 48 males and 48 females aged 20-70 years referred to the Radiology Department. Two variables showed significant differences: Cephalo-caudal and size of the left maxillary sinus. The study concluded that the correct predictive accuracy was $70.8 \%$ in males and $62.5 \%$ in females. In conclusion, MDCT measurements of cephalo-caudal and size of the left maxillary sinuses are useful feature in gender determination in Egyptians. ${ }^{[7]}$ The present study was in consistent with the other studies; males have larger maxillary sinus when compared with females.

\section{CONCLUSION}

Gender determination is an important step in identification in forensic medicine. Maxillary sinus dimensions measurements are valuable in studying sexual dimorphism. They tend to stabilize after second decade of life and the radiographic images could provide adequate measurements for maxillary sinuses that cannot be approached by other means. Hence, morphometric analysis of maxillary sinuse can assist in gender determination. However, this is a preliminary study further studies on large sample size is desirable.

\section{REFERENCES}

1. Teke HY, Duran S, Canturk N, Canturk G. Determination of gender by measuring the size of the maxillary sinuses in computerized tomography scans. Surg Radiol Anat 2007;29:9-13.

2. Uthman AT, Al-Rawi NH, Al-Naaimi AS, Al-Timimi JF. Evaluation of maxillary sinus dimensions in gender determination using helical CT scanning. J Forensic Sci 2011;56:403-8.

3. Fernandes CL. Forensic ethnic identification of crania: The role of the maxillary sinus - A new approach. Am J Forensic Med Pathol 2004;25:302-13.

4. Amusa YB, Eziyi JA, Akinlade O, Famurewa OC, Adewole SA, Nwoha PU, et al. Volumetric measurements and anatomical variants of paranasal sinuses of Africans (Nigerians) using dry crania. Int $\mathrm{J}$ Med Med Sci 2011;3:299-303.

5. Sharan A, Madjar D. Maxillary sinus pneumatization following extractions: A radiographic study. Int $\mathrm{J}$ Oral Maxillofac Implants 2008;23:48-56.

6. Kim GR. A morphological study of the paranasal sinuses in Koreans. Yonsei Med J 1962;3:11-7.

7. Amin MF, Hassan EI. Sex identification in Egyptian population using Multidetector Computed Tomography of the maxillary sinus. J Forensic Leg Med 2012;19:65e-9.

How to cite this article: Sidhu R, Chandra S, Devi P, Taneja N, Sah K, Kaur N. Forensic importance of maxillary sinus in gender determination: A morphometric analysis from Western Uttar Pradesh, India. Eur J Gen Dent 2014;3:53-6.

Source of Support: Nil, Conflict of Interest: None declared.

\section{"Quick Response Code" link for full text articles}

The journal issue has a unique new feature for reaching to the journal's website without typing a single letter. Each article on its first page has a "Quick Response Code". Using any mobile or other hand-held device with camera and GPRS/other internet source, one can reach to the full text of that particular article on the journal's website. Start a QR-code reading software (see list of free applications from http://tinyurl.com/ yzlh2tc) and point the camera to the QR-code printed in the journal. It will automatically take you to the HTML full text of that article. One can also use a desktop or laptop with web camera for similar functionality. See http://tinyurl.com/2bw7fn3 or http://tinyurl.com/3ysr3me for the free applications. 